lems of getting equipment and financing support staff in the MRLs and MRGs are debated here, as is the expected role of particular families of materials and processes in particular industries (nearnet-shape manufacture, ceramics in heat-engines, surface modification, molecular-beam epitaxy and so on). Several contributors make points which would risk provoking cynical shrugs in Britain today: Albert Clogston, late of Bell Laboratories, insists on the crucial importance of basic technology in research and development laboratories, while Praveen Chaudhari, a senior research manager at IBM, declares that "an important point which cannot be taken for granted or emphasized enough is that the research enterprise of the nation requires an infrastructure that nurtures general science, or science that cannot be identified at present with any particular area of application". This comes from an industrialist, not from an academic!

Earlier in the book, Sproull emphasizes how the MRLs were based on the postwar recognition that Government contracts and grants "should provide much more scope for the contractor's imagination and discovery and more harvesting by informal agency-contractor interactions rather than by fulfilling specifications", and that the Office of Naval Research (one of the progenitors of the MRLs) favoured "task statements in general terms, with maximum opportunity for creation and discovery". In spite of the temporary setback of the Mansfield Amendment, the United States has by and large been able to keep these ideals. Certainly, it seems that Senator Mansfield has had a less baleful influence than Lord Rothschild in Britain.

For non-American readers, there are some longueurs in the book because it concentrates exclusively on the United States and its achievements. But the diet is by no means an unvaried one of selfcongratulation. DiSalvo bewails the neglect of the creation (synthesis) of novel bulk materials and compares it with the French penchant, orchestrated by the Centre National de la Recherche Scientifique, for combining synthesis of novel materials with immediate assessment of properties, often in the same laboratory. This is one of several places in the book where the need is pressed for materials scientists to give more attention to solidstate chemistry.

This volume represents a landmark in the literature of materials science and engineering. It deserves a wide readership, not only among materials practitioners but also among specialists in science policy.

Robert W. Cahn is in the Department of Materials Science and Metallurgy, University of Cambridge, Pembroke Street, Cambridge CB2 $3 Q Z, U K$.

\section{Life of the running waters}

\section{J. Green}

The Ecology of River Systems. Edited by B.R. Davies and K.F. Walker. $\mathrm{Dr} W$. Junk: 1986. Pp.793. Dfl. 350, \$148, 997.

THE study of river ecology came of age only 17 years ago with the publication of Noel Hynes's The Ecology of Running Waters. It is most appropriate, then, that Hynes has written the foreword to the present book. Together with the introduction by the editors, he provides the integrating part of the book, distilling into a few pages the modern approach to the subject. There has been a gradual realization that a river system needs to be seen in relation to its entire catchment area - lakes, reservoirs and floodplains are essential components of any study. The emphasis throughout the book is therefore rightly on the drainage basin as a whole, and where dams have been built they are given their fair share of attention.

The main part of the book deals with the ecology of 13 major rivers outside Europe. Africa is best covered, with six, the Americas are next with five, while Australia and Asia have but one each. A huge amount of information is included, much of it not readily available elsewhere, and certainly not in the readable form that has been achieved by most of the authors.

The great value of these accounts is that they enable ecologists to make their own comparisons, between the systems described here or with some other river system on which they may be working. The gaps in each of the contributions reflect the current state of our knowledge, and by clarifying just how much, or how little, we know, the individual chapters should stimulate further research. One of the points to emerge is that for nearly half of these large rivers we do not have basic information on all the main components such as the aquatic plants, plankton, benthos and fishes. Filling these lacunae in knowledge will not be an easy matter; sampling benthos, for example, requires boats, heavy equipment and considerable manpower for sorting, and few governments are willing to give priority to such work.

From the biogeographical point of view, we require similar accounts of yet other rivers. This is not an advocation of a purely empirical approach. For our understanding of river systems to develop to a stage where generalizations and predictions may be possible, we need basic comparative data on rivers from a wide range of climatic and geological conditions. Is it too much to hope that in ten years' time we may get another book dealing, say, with the Indus, Ganges, Irrawaddy, Yangtze, Amur, Lena, Yenisei and $\mathrm{Ob}$ ? That would form a fascinating series, and if the Mississippi and Orinoco were added we would then have, combined with the present book, the foundations for a fully scientific appreciation of some of the most vital and misused parts of our planet.

J. Green is a Professor in the School of Biological Sciences, Queen Mary College, Mile End Road, London E1 $4 N S$, UK.

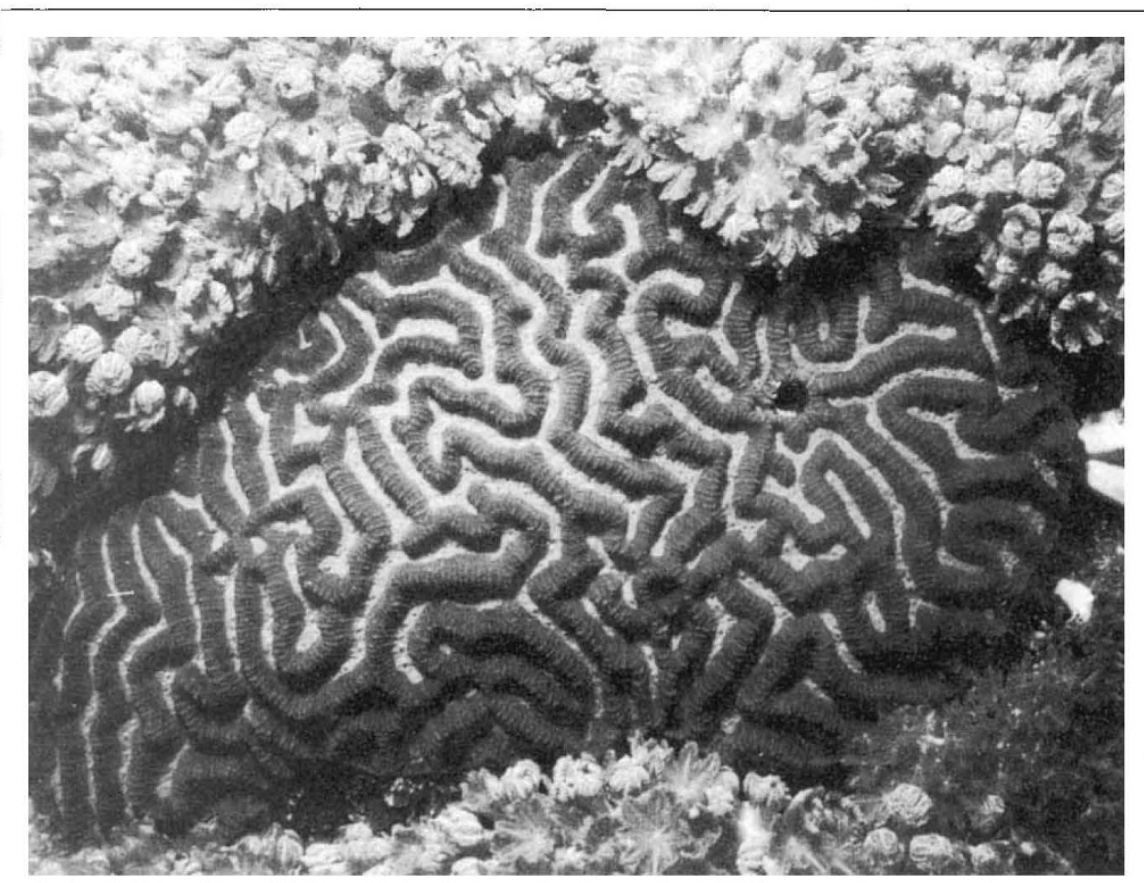

Labyrinthine life - Platygyra daedalea, a brain coral which forms colonies a metre or more in diameter. The picture is a black-and-white reproduction of a colour photograph in Red Sea Invertebrates by Peter Vine, a large-format, beautifully illustrated book recently published by IMMEL, Ely House, 37 Dover Street, London WIX 3RB, UK. Price is £39.50. 